\title{
Syncope with Inducible Ventricular Tachycardia by ECG Finding
}

National Cancer Institute

\section{Source}

National Cancer Institute. Syncope with Inducible Ventricular Tachycardia by ECG Finding. NCl Thesaurus. Code C100019.

An electrocardiographic finding of ventricular tachycardia accompanied by syncope in the individual. 